\title{
Thermochemistry of phosphate glasses for immobilization of dangerous waste
}

\author{
Pawel Stoch · Malgorzata Ciecinska
}

MEDICTA2011 Conference Special Chapter

(C) The Author(s) 2011. This article is published with open access at Springerlink.com

\begin{abstract}
Vitrification is currently considered to be an effective method for immobilization of radioactive waste. It is based on the enclosing of harmful elements in the structure of the glass. This work presents the results of studies on the thermal properties of glasses from $\mathrm{P}_{2} \mathrm{O}_{5}$ $\mathrm{Al}_{2} \mathrm{O}_{3}-\mathrm{Na}_{2} \mathrm{O}$ and $\mathrm{P}_{2} \mathrm{O}_{5}-\mathrm{Al}_{2} \mathrm{O}_{3}-\mathrm{Fe}_{2} \mathrm{O}_{3}-\mathrm{Na}_{2} \mathrm{O}$ systems for rendering nuclear waste in the form of salts such as sulfates, halides, and phosphates with high sodium content. These substances are not accepted by borosilicate glass, commonly used up to now for nuclear waste immobilization. Formation of sinters of glass-waste mixtures was selected as the method for immobilization, and the thermal chemistry of this process was studied. $\mathrm{CaCl}_{2}$ was used as the model chloride waste substance. The process of immobilization consists of its sintering with $\mathrm{Na}, \mathrm{Al}, \mathrm{Fe}-$ phosphate glasses containing more than $50 \mathrm{wt} \% \mathrm{P}_{2} \mathrm{O}_{5}$ as the amorphous matrix. Thermal analysis showed that all glasses exhibit an ability for crystallization, with that the intensiveness of this process is determined by the chemical composition of these glasses. The addition of $\mathrm{Fe}_{2} \mathrm{O}_{3}$ to the glass intensified crystallization process. Leaching of components of sinters tests established that glass containing $\mathrm{Fe}_{2} \mathrm{O}_{3}$ in its composition most effectively binds waste in comparison to $\mathrm{Al}_{2} \mathrm{O}_{3}$ containing phosphate glass. The test results allow for the statement that the waste substance in the form of chloride salts such as $\mathrm{CaCl}_{2}$ is stable bound in the glass-crystalline sinters, which ensures its effective immobilization.
\end{abstract}

\section{P. Stoch $(\square) \cdot$ M. Ciecinska}

Faculty of Materials Science and Ceramics, AGH, University of Science and Technology, Al. Mickiewicza 30, 30-059 Krakow, Poland

e-mail: p.stoch@cyf.gov.pl
Keywords Glass - Glass-ceramic - Phosphate glasses · Waste vitrification · Dangerous waste immobilization

\section{Introduction}

Glasses and glass-ceramic materials currently find applications in various fields of science and technology. As of now, the current task is the utilization of glasses and glassceramics for the immobilization of harmful waste substances containing toxic elements. Intensive studies on methods of effective immobilization and storage of radioactive waste by vitrification procedure have been conducted for many years. The vitrification of this waste is considered to be especially effective method [1-4]. This is process that is based on enclosing the waste in the structure of the glass. The capacity of the glass structure to accept various components and form a common network is advantage of in this process. Components not forming common chemical compounds or forming unstable compounds can also be incorporated into the glass network. An example of this are glasses containing oxides and nitrides, oxides and carbides, oxides and fluorides, $\mathrm{P}_{2} \mathrm{O}_{5}$ and $\mathrm{SiO}_{2}$, $\mathrm{TiO}_{2}$, and $\mathrm{SiO}_{2}$ and other substances in their structures [5].

The composition of glass used for immobilization of waste is to guarantee the strong binding of the elements introduced to the glass by means of chemical bonds with the vitreous matrix structure. For this reason, the type of compound containing dangerous element should be taken into consideration. Silicate glasses have difficulty in accepting salts into their structure (e.g., sulfides, chlorides) due to the effect of non-mixing taking place at the molten state of the glass, which is known as liquation. Under such conditions, these salts precipitate in the form of a separate phase. Nitrides and chlorides decompose during melting, 
giving off gaseous nitrogen and chlorine. Certain metals (molybdenum, chromium, vanadium and wolfram) and their oxides exhibit limited solubility in glasses. This is why it is significant to adapt the chemical composition and properties of vitreous materials to the form of the introduced waste, its amount as well as to the technical process of the waste immobilization $[1,3,4]$.

For these purposes, glasses melting in low temperatures are needed which have the capacity to accept harmful waste into their structure not only in oxide form, but also in the form of salts such as chlorides, sulfides or phosphates, with their components becoming permanently built into the structure of the glass. According to available data, these requirements are met by $\mathrm{Al}, \mathrm{Fe}$ phosphate glasses $[3,4,6]$, and these glasses were selected for study. It was also decided that mechanical activation of glasses by means of long-term grinding as the method for increasing their reactivity, was to be used. Mechanical activation decreases the melting temperature, increases glass homogeneity and quickens and intensifies crystallization. An increase of the specific surface area and surface energy of the glass also takes place. This allows for the obtainment of a fine crystalline glass-ceramic stably binding the harmful waste $[7,8]$. All of this should make it possible to encapsulate the waste in the glass matrix through sintering of the mixture of pulverized glass and waste as the method for immobilization. Currently, the method generally used is the method of co-melting of glass and waste. This requires higher temperatures, which increases energy consumption and causes emission of volatile components.

\section{Experimental}

Glasses with a $\mathrm{P}_{2} \mathrm{O}_{5}-\mathrm{Na}_{2} \mathrm{O}-\mathrm{Al}_{2} \mathrm{O}_{3}$ system, containing more than $50 \mathrm{wt} \%$ of glass-forming $\mathrm{P}_{2} \mathrm{O}_{5}$, were subjected to study. In addition, this composition was modified by the addition of $\mathrm{Fe}_{2} \mathrm{O}_{3}$ in the amount of 15 wt\% with a corresponding decrease in $\mathrm{Al}_{2} \mathrm{O}_{3}$ content. The chemical compositions of glasses are based on the work of Donald et al. [6] and are shown in Table 1.

Glass synthesis was carried out using the method of melting of the set of raw materials, composed of Na- and $\mathrm{NH}_{4}$-phosphates, $\mathrm{Al}_{2} \mathrm{O}_{3}$ and $\mathrm{Fe}_{2} \mathrm{O}_{3}$ of reagent purity, in an electric furnace at a temperature of $1,050{ }^{\circ} \mathrm{C}$, for $2 \mathrm{~h}$. The melt was poured onto a steel plate for it to vitrify. Glass samples were not annealed. The glasses were initially broken up and then pulverized and activated by grinding in the Pulverisette 6 ball mill of the Fritsch company at a speed of $250 \mathrm{rpm}$ for a period of $20 \mathrm{~min}, 2 \mathrm{~h}$, and $4 \mathrm{~h}$. Mixtures of glass $(90 \mathrm{wt} \%)$ and calcium chloride (10 wt $\%$ ), were made from the obtained glass powders. Next, $1.5 \mathrm{~cm}$ diameter pastilles were formed from these
Table 1 Chemical composition of the investigated glasses

\begin{tabular}{lcc}
\hline Component & \multicolumn{2}{c}{ Content in glass/wt\% } \\
\cline { 2 - 3 } & $\mathrm{Aa}$ & $\mathrm{Ac}$ \\
\hline $\mathrm{P}_{2} \mathrm{O}_{5}$ & 55.6 & 52.1 \\
$\mathrm{Na}_{2} \mathrm{O}$ & 24.9 & 23.3 \\
$\mathrm{Al}_{2} \mathrm{O}_{3}$ & 19.5 & 9.8 \\
$\mathrm{Fe}_{2} \mathrm{O}_{3}$ & - & 14.8 \\
$\mathrm{~B}_{2} \mathrm{O}_{3}$ & - & - \\
\hline
\end{tabular}

mixtures in a hydraulic press under a pressure of $15 \mathrm{MPa}$. These were sintered for $2 \mathrm{~h}$ in the temperature of glass crystallization, determined from the DSC curve.

For the purpose of examination of the thermal properties of the glass-waste mixtures, their thermal analysis was carried out. Measurements were taken using the STA 449 Jupiter F3 apparatus of the Netzsch company. Samples of a mass of $50 \mathrm{mg}$ were placed in the platinum crucibles of the apparatus and heated at a rate of $10{ }^{\circ} \mathrm{C} / \mathrm{min}$. The measurement was carried out in a $\mathrm{N}_{2}$ atmosphere. Crystallization of the mixtures was realized in an electric tube furnace in temperatures determined from the DTA curves, and these temperatures were maintained for a period of $2 \mathrm{~h}$. The progression of glass crystallization was controlled using a scanning electron microscope (SEM) and EDS analysis of the chemical composition (FEI Nova NanoSEM 200). Crystalline phases created during heat treatment of samples, were determined using the DSH method by means of an X-ray diffractometer (DRON-1.5) for $\mathrm{CuK}_{\alpha}$ radiation $(\lambda=1.54 \AA)$.

The leaching of components from sinters was determined. For this purpose, the procedure used for measurement of hydrolytic durability of glasses was applied. The test was based on leaching of components from a $2 \mathrm{~g}$ sinter sample crushed to a grain size of $0.3-0.5 \mathrm{~mm}$ by means of keeping the sample in deionized water with a degree of purity of 2 for $60 \mathrm{~min}$ at a temperature of $98{ }^{\circ} \mathrm{C}$. For determination of the content of components in the extract, the ICP-AES Optima 7300 DV Perkin-Elmer plasma spectrophotometer with inductive plasma excitation was used.

\section{Results}

In order to study the process of immobilization of calcium chloride, as the model waste, by the glass, a mixture of calcium chloride with glass was used. Each mixture contained $\mathrm{CaCl}_{2}$ in the amount of $10 \%$ of the total mass of the mixture. The mixtures were subjected to thermal analysis for the purpose of determining the processes occurring 
within them during thermal treatment and for the determination of sintering temperature.

The thermal analyses of mixtures containing Aa or Ac glass in their non-activated are similar. In the temperature range of $100-143{ }^{\circ} \mathrm{C}$, endothermic effects related to the dehydration of calcium chloride are observable on the curves. This was accompanied by a loss of mass registered on TG curves equal to $6 \mathrm{wt} \%$ for the sample with Aa glass and $13 \mathrm{wt} \%$ for the Ac glass-containing sample.

The endothermic effect of the transformation of the Aa glass as component of mixture occurs at a temperature of $413{ }^{\circ} \mathrm{C}$; however, for the Ac glass containing $\mathrm{Fe}$ in its composition, this effect occurred at $460{ }^{\circ} \mathrm{C}$.

In the temperature range of $540-555{ }^{\circ} \mathrm{C}$, the DTA curves of the mixtures showed exothermic effects caused by glass crystallization. Strong endothermic effects in the range of about $660-766{ }^{\circ} \mathrm{C}$ are the result of melting of compounds re-crystallized in the previous temperature range.

Thermal curves (DSC, TG) of mixtures of mechanically activate glasses and $10 \mathrm{wt} \% \mathrm{CaCl}_{2}$ are shown in Figs. 1 and 2. In the case of the mixture containing Aa glass, lengthening of the time of glass activation is accompanied by an increase in the dehydration endothermic effect toward higher temperatures. For the mixture with the Aa glass, activated for $20 \mathrm{~min}$, the temperature of the beginning of the first effect was $76^{\circ} \mathrm{C}$; for the activation time of $2 \mathrm{~h}, 87^{\circ} \mathrm{C}$; and for activation lasting $4 \mathrm{~h}, 89^{\circ} \mathrm{C}$. These effects were accompanied by correspondingly diminishing mass of sample. With that, the loss of mass for the mixture with Aa glass activated for $4 \mathrm{~h}$, was equal to $22.53 \mathrm{wt} \%$.

Mechanical activation of the glass resulted in a decrease of the transformation temperature (Tg). For exothermic effect crystallization temperatures the lowest exhibited by the Aa glass activated for $2 \mathrm{~h}\left(515^{\circ} \mathrm{C}\right)$ was observed and for longer activation time $(4 \mathrm{~h})$ this effect was observed at higher temperature $\left(533{ }^{\circ} \mathrm{C}\right)$. The endothermic effect related to the melting of re-crystallized phases in the glass also changes depending on the time of grinding in similar way as the crystallization effect, and for $2 \mathrm{~h}$ of activation, progresses in the lowest temperature $\left(660{ }^{\circ} \mathrm{C}\right)$.

Thermal curves of mixtures of $10 \% \mathrm{CaCl}_{2}$ and Ac glass, with ferric oxide in the amount of $14.9 \mathrm{wt} \%$ and correspondingly decreased $\mathrm{Al}_{2} \mathrm{O}_{3}$ content, are shown in Fig. 2. They show the endothermic effect related to the removal of water at a temperature of $\sim 70{ }^{\circ} \mathrm{C}$. The process of glass crystallization has two stages, and mechanical activation decreased the crystallization temperature. The formed phases melt about $780{ }^{\circ} \mathrm{C}$.

TG curves for all mixtures, starting from a temperature of $200{ }^{\circ} \mathrm{C}$, exhibit a slight, gradual mass diminishing, with its speed increasing above the $\mathrm{Tg}$ temperature. It exceeds, in the range of crystallization, and especially above the

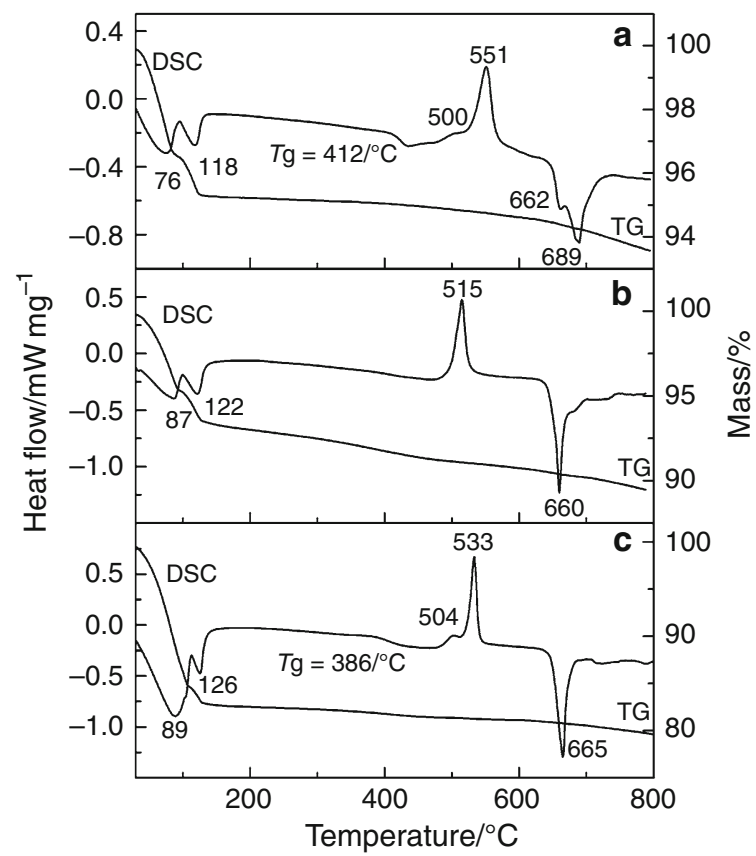

Fig. 1 DSC and TG curves of mixtures $\mathrm{CaCl}_{2}(10 \mathrm{wt} \%)$ and Aa glass (90 wt\%) mechanically activated $20 \mathrm{~min}(\mathbf{a}), 2 \mathrm{~h} \mathrm{(b)}$ and $4 \mathrm{~h}$ (c)

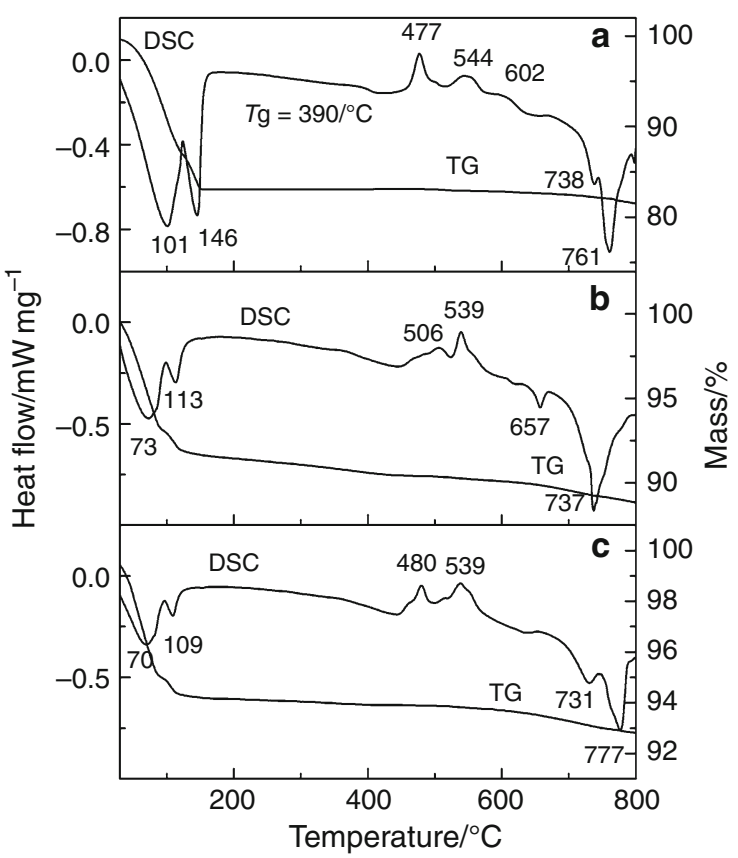

Fig. 2 DSC and TG curves of mixtures $\mathrm{CaCl}_{2}(10 \mathrm{wt} \%)$ and Ac glass (90 wt\%) mechanically activated $20 \mathrm{~min}(\mathbf{a}), 2 \mathrm{~h} \mathrm{(b)}$ and $4 \mathrm{~h}$ (c)

endothermic effect of melting of crystalline compounds in glass. This phenomenon can be explained by the escape of chlorine accompanying the reaction of $\mathrm{CaCl}_{2}$ with glass components.

XRD analysis of sinters with the Aa glass showed crystallization $\mathrm{AlPO}_{4}$ and also sodium aluminate $\mathrm{Na}$ 
Table 2 The normalized sinter components release rate, $\mathrm{NL}_{\mathrm{i}} / \mathrm{g} \mathrm{m}^{-2}$

\begin{tabular}{lccccc}
\hline Sample & $\mathrm{NL}_{\mathrm{P}}$ & $\mathrm{NL}_{\mathrm{Al}}$ & $\mathrm{NL}_{\mathrm{Fe}}$ & $\mathrm{NL}_{\mathrm{Ca}}$ & $\mathrm{NL}_{\mathrm{Na}}$ \\
\hline $\begin{array}{l}\text { Sinter: glass Aa and 10\% } \\
\quad \mathrm{CaCl}_{2}\end{array}$ & 20.98 & 8.31 & - & 8.33 & 139.92 \\
$\begin{array}{l}\text { Sinter: glass Ac and 10\% } \\
\mathrm{CaCl}_{2}\end{array}$ & 11.14 & 2.34 & 0.49 & 4.28 & 156.53 \\
\hline
\end{tabular}

Table 3 The normalized components release rate, $\mathrm{NL}_{\mathrm{i}} / \mathrm{g} \mathrm{m}^{-2}$ from activated glass containing sinters

\begin{tabular}{|c|c|c|c|c|c|}
\hline Sinter & $\mathrm{NL}_{\mathrm{P}}$ & $\mathrm{NL}_{\mathrm{Al}}$ & $\mathrm{NL}_{\mathrm{Fe}}$ & $\mathrm{NL}_{\mathrm{Na}}$ & $\mathrm{NL}_{\mathrm{Ca}}$ \\
\hline $\begin{array}{l}\text { Glass } \mathrm{Aa}(20 \text { min act })+ \\
10 \% \mathrm{CaCl}_{2}\end{array}$ & 18.51 & 1.77 & - & 130.32 & 2.77 \\
\hline $\begin{array}{l}\text { Glass } \mathrm{Aa}(4 \mathrm{~h} \text { act })+ \\
10 \% \mathrm{CaCl}_{2}\end{array}$ & 15.50 & 1.56 & - & 125.87 & 1.83 \\
\hline $\begin{array}{l}\text { Glass Ac }(20 \text { min act })+ \\
10 \% \mathrm{CaCl}_{2}\end{array}$ & 9.10 & 2.21 & 0.293 & 109.139 & 0.895 \\
\hline $\begin{array}{l}\text { Glass Ac }(4 \mathrm{~h} \text { act })+ \\
10 \% \mathrm{CaCl}_{2}\end{array}$ & 4.94 & 1.21 & 0.02 & 102.08 & 0.39 \\
\hline
\end{tabular}

$\mathrm{Al}_{11} \mathrm{O}_{17}$ in glass. As a result of the reaction with $\mathrm{CaCl}_{2}$, calcium aluminate $\mathrm{CaAl}_{4} \mathrm{O}_{7}$ was formed. Sodium chloride and sodium chlorate was also formed. In addition, sinters of $\mathrm{Ac}$ glasses contained the $\mathrm{FeAl}_{2} \mathrm{O}_{4}$ aluminate.

The results of EDS point analysis of sinters of the Aa glass are consistent with the results of X-ray analysis. This analysis confirmed the presence of sodium chloride and chlorate as well as aluminum phosphate (berlinite). In the case of sinters with the Ac glass, besides sodium chloride, the presence of an aluminum-calcium phosphate and of ferric chloride were observed as products of the reaction with $\mathrm{CaCl}_{2}$.

The results of the leaching test for components of the sinters have been presented as standardized leaching coefficients [9], calculated according to the formula:

$\mathrm{NL}_{i}=\frac{\left(C_{i} \cdot V\right)}{\left(\mathrm{SA} \cdot f_{i}\right)}$

where $\mathrm{NL}_{i}$ is the standardized leaching coefficient of element $i\left[\mathrm{~g} / \mathrm{m}^{2}\right], C_{i}$ is the concentration of element $i$ in the solution $\left[\mathrm{g} / \mathrm{m}^{3}\right], V$ is the solution volume $\left[\mathrm{m}^{3}\right], f_{i}$ is the weight percentage of the $i$ element in the sample, SA is the surface of the tested sample $\left(\mathrm{m}^{2}\right)$.

The values of the standardized leaching coefficient for components of non-activated glasses sintered with $\mathrm{CaCl}_{2}$ fulfilling the role of a waste substance have been listed in Table 2.

In the case of each of the sinters subjected to testing, the leaching of the calcium simulating the dangerous waste was slight. However, sinters with the Ac glass clearly exhibited lower leaching of $\mathrm{Ca}$ and other components besides sodium.
Among the sinters of mechanically activated glasses, sinters with glasses activated for $20 \mathrm{~min}$ and $4 \mathrm{~h}$ were selected for determination of component leachability (Table 3).

The obtained results show that mechanical activation of glass decreases calcium leaching and leaching of another glass components. Length of the time of mechanical activation of glasses results in a decrease of standardized $\mathrm{NL}_{\mathrm{i}}$ coefficient values. The sinter with Ac glass containing 14.9\% $\mathrm{Fe}_{2} \mathrm{O}_{3}$ is characterized by a significantly lower leaching of components, especially of $\mathrm{Ca}$. The leaching of $\mathrm{Fe}$ is also incomparably smaller in relation to $\mathrm{Al}$. The large $\mathrm{Na}$ content in the solution is caused by the presence of $\mathrm{NaCl}$ formed during sintering and $\mathrm{CaCl}_{2}$ with glass surface interaction.

\section{Conclusions}

The results of the conducted tests confirmed that sintering of the waste in the form of a chloride with $\mathrm{Na}, \mathrm{Al}, \mathrm{Fe}$ phosphate glasses can be an effective method for immobilization of hazardous waste in the form of chlorides. The effectiveness of immobilization is considerably increased by mechanical activation of the glass used as a sintering component. The sintering of the phosphate glass-and waste mixture is accompanied by complex chemical reactions. Crystallization of the glass and its reaction with $\mathrm{CaCl}_{2}$ takes place above the glass transformation temperature at about $460{ }^{\circ} \mathrm{C}$. Presence of $\mathrm{AlPO}_{4}$ and also of sodium aluminate $\mathrm{NaAl}_{11} \mathrm{O}_{17}$ as glass crystallization products was stated in the sinters, and for glass containing ferric oxide, also of the $\mathrm{FeAl}_{2} \mathrm{O}_{4}$ aluminate. As a result of the reaction with $\mathrm{CaCl}_{2}$, the $\mathrm{CaAl}_{4} \mathrm{O}_{7}$ calcium aluminate was formed. Sodium chloride and sodium chlorate were also formed. Sintering is accompanied by the emission of chlorine. Its intensiveness increases above the $\mathrm{Tg}$ temperature and is exceeded, in the range of crystallization temperatures, and especially above the endothermic effect of melting of formed crystalline compounds. This is a result of the double components exchange reaction between the $\mathrm{CaCl}_{2}$ and the glass.

Leaching measurement results showed high effectiveness of immobilization of $\mathrm{Ca}$ through sintering with phosphate glass. Mechanical activation of the glass considerably decreases leaching of calcium as well as of components of sinters. Lengthening of the time of mechanical activation of glasses results in a clear decrease of standardized leaching coefficient values. The sinter with Ac glass containing 14.9\% $\mathrm{Fe}_{2} \mathrm{O}_{3}$ is characterized by a significantly lower leaching of components, especially of $\mathrm{Ca}$. The leaching of $\mathrm{Fe}$ is also incomparably smaller in relation to $\mathrm{Al}$.

The optimization of the applied process of immobilization encompassing glass composition, its activation and sintering conditions will be the subject of further studies. 
Acknowledgements The work was supported by Project NN507458037 of the Ministry of Science and Higher Education of Poland.

Open Access This article is distributed under the terms of the Creative Commons Attribution Noncommercial License which permits any noncommercial use, distribution, and reproduction in any medium, provided the original author(s) and source are credited.

\section{References}

1. Ojovan MI, Lee WE. An introduction to nuclear waste immobilsiation. Amsterdam: Elsevier-Science, 2005.

2. Stoch P. Vitrification of radioactive hospital waste incineration ash. In: WM2009 Conference. Phoenix: Phoenix Convention Center; 2009. p. 9149(1)-9149(7).
3. Stoch P. Cs containing borosilicate waste glasses. Opt Appl. 2008; 38:237-43.

4. Ojovan MJ, Lee WE. Glass wasteforms for nuclear waste immobilization. Metall Mater Trans A. 2011;42A:837-51.

5. Stoch L. Structure and crystallization of multicomponent glasses. High Temp Mater Process. 1992;10:245-64.

6. Donald IW, Metcalfe BL, Taylor RNJ. The immobilization of high level radioactive wastes in ceramics and glasses. J Mater Sci. 1997; 32:5851-87.

7. Ciecinska M. Thermal analysis of mechanical activated glass. J Therm Anal Calorim. 2006;84:593-600.

8. Ciecinska M, Stoch P. Mechanical activated bioglass-ceramics. In: Proceedings of XX International Congress on Glass. Kyoto: ICG; 2004. p. P-12-013-P-12-018.

9. Choi K, Sheng J, Lee MC, Song MJ. Utylizing the KEP-A glass to vitrify low-level radioactive waste from Korean NPPS. Waste Manag. 2000;20:575-80. 